\title{
Comparação das Características Físico-Químicas do Fluido de Corte Aplicado no Torno CNC Utilizado em Laboratório Didático - Estudo de Caso
}

\author{
Filipe Y. G. Luz, Bruno S. Miranda, João V. M. Torres, \\ Marcio J. Dias, Sérgio M. Brandão \& Adriano P. Ramiro
}

Usinagem é um processo de fabricação que continua evoluindo constantemente. $\mathrm{O}$ objetivo deste artigo é avaliar e comparar as características físico-químicas dos fluidos de corte coletados periodicamente em um torno $\mathrm{CNC}$ do Laboratório didático do Centro Universitário de Anápolis - UniEVANGÉLICA. Para execução deste foi verificado a compatibilidade com as fichas técnicas dos fabricantes para montagem de um laudo de avaliação. Foi constatado que, por ser tratar de um equipamento industrial aplicado para fins didáticos e consequentemente operar poucas horas no mês, os fluidos tiveram uma degradação excessiva, sendo estes fatores de risco ao maquinário.

Palavras chave: fluido de corte; torno CNC; meio ambiente; características físicoquímicas.

The machining process is a manufacturing process that continues to evolve constantly. The purpose of this is to evaluate and compare the physical-chemical characteristics of the cutting fluids collected periodically in a CNC lathe at the Didactic Laboratory of the University Center of Anápolis - UniEVANGÉLICA. In order to execute this, it was verified the compatibility with the manufacturers' technical sheets for assembling an appraisal report. It was found that, because it is an industrial equipment applied for educational purposes and consequently operating a few hours in the month, the fluids had an excessive degradation, being these risk factors to the machinery.

Keywords: cutting fluid; CNC lathe; environment; physical and chemical characteristics. 


\section{Introdução}

\section{PROCESSOS DE USINAGEM}

Sabe-se que com a Revolução Industrial, alguns novos materiais e vários tipos de liga foram sendo descobertos. Em meados do século XVIII, o material mais utilizado em engenharia era a madeira. Já no início do século XIX, com a utilização da água e do vapor, acabou por vez impulsionando a indústria metal-mecânica. No século XX, necessitou-se fabricar peças de materiais mais resistentes e, para isso, foi necessário que aprimorar também o maquinário utilizado. Com o crescimento da tecnologia, o desenvolvimento de ferramentas que conseguissem usinar tais materiais fora facilitado. Diante de todo o avanço da tecnologia, as máquinas comandadas numericamente (CN) surgiram, promovendo a produção em série e tendo consequentemente, um ganho considerável de tempo em relação as máquinas convencionais, mantendo também, a qualidade da usinagem ${ }^{1}$.

A usinagem é um processo de retirada de sobremetal de uma determinada peça por meio da utilização de ferramentas de corte. Estas ferramentas podem ser: manuais ou máquinas operatrizes. Dentre algumas das ferramentas manuais estão cossinetes, alargadores, limas e machos. Das principais máquinas operatrizes dos processos de usinagem, podem-se destacar o torno mecânico universal, fresadora mecânica universal, retificadora plana, cilíndrica e centerless, mandriladora e furadeira ${ }^{1}$.

A caracterização mecânica dos materiais tem de ser assegurada, uma vez que, este interfere diretamente nos parâmetros que podem ser mensuráveis como: qualidade superficial da peça, produtividade, temperatura de corte, força de usinagem, tipo de cavaco e vida útil da ferramenta. Pode-se entender por este processo como usinabilidade, sendo a propensão do material em ser cortado, torneado, fresado, furado ou rosqueado. Para melhor compreendimento da funcionalidade do fluido de corte nestes processos, é necessário compreender a origem da utilização destes, que é o ponto onde muitos autores relatam e descrevem seus atributos ${ }^{2}$.

\section{HISTÓRICO FLUIDO DE CORTE}

Sabe-se que, Frederick Winslow Taylor foi o pioneiro na introdução de fluidos de corte na usinagem dos materiais. Por volta de 1890, ele utilizou água no processo, percebendo assim algumas melhorias na refrigeração na região peçaferramenta e um aumento de $33 \%$ na velocidade de corte, sem alterar a vida útil. Contudo, como já é esperado, por mais que a água traga os benefícios já citados, ao entrar em contato com metais ou ligas-metálicas, ela promove a oxidação, tanto da peça, quanto da ferramenta ${ }^{3,4}$.

A partir disto, foi aos poucos sendo testada a substituição da água, como fluido de corte, por óleos, como os óleos graxos de origem animal que fizeram sucesso na época, sendo utilizados em basicamente todas as operações que exigiam baixos parâmetros de usinagem. Entretanto, como esses óleos eram de origem animal, apresentaram uma baixa vida útil, deteriorando-se rapidamente, principalmente, quando aplicados em altas temperaturas ${ }^{3}$.

Com este agravante e o aumento da produção de materiais metálicos, foram surgindo, aos poucos, os óleos minerais, que primeiramente foram aplicados em operações com materiais de baixa resistência mecânica (ligas não ferrosas e aços leves), e para operações que exigiam maiores esforços, eram adicionados óleos de origem animal, que foram reduzidos drasticamente do processo por meio de avanços tecnológicos envolvendo metais e ligas metálicas, ferramentas de usinagem e obviamente, fluidos de corte. Para satisfazer às operações consideradas pesadas (aços com maior teor de carbono), foram disseminados a aplicação de aditivos químicos, surgindo assim uma variada gama de combinações de óleos (minerais e graxos), fluidos químicos de corte e também as emulsões, sendo sua finalidade definida de acordo com as exigências do processo ${ }^{3}$.

A classificação dos tipos de fluido de corte não segue uma padronização, alguns autores fazem suas categorizações apenas dentro da classe dos fluidos de corte no estado líquido, dividindo em: óleos puros e óleos não puros (miscíveis em água). Outros autores adotam em seus catálogos, os fluidos de corte sólidos e gasosos, sendo referidos principalmente em literaturas técnicas. Baseado 
na bibliografia de FERRARESI (2017) ${ }^{3}$, o autor descreve os fluidos de corte de acordo com seus três estados físicos que facilitam no agrupamento destes, sendo esses estados: sólidos, líquidos e gasosos.

\section{TIPOS DE FLUIDOS DE CORTE}

De acordo com suas características físicas, os fluidos de corte possuem funções diferentes. Os fluidos de corte sólidos (Grafita e bissulfeto de molibdênio), são utilizados para diminuir o atrito entre ferramenta/peça/cavaco, porém, necessitam de aplicação constante durante o processo, o que o inviabiliza, pois o equipamento deve ser desligado para isso. O emprego de fluidos de corte gasosos, possui finalidade apenas de remoção do cavaco, sendo que, na maior parte dos processos, é utilizado o ar comprimido. Porém alguns autores citam a utilização destes (ar, $\mathrm{CO}_{2}$ e $\mathrm{N}_{2}$ ) para obter refrigeração e uma mínima quantidade de lubrificação, estas propriedades são obtidas quando aplicadas em baixas temperaturas juntamente com aumento da pressão, entretanto, seu custo é aumentado a ponto de tornar-se inviável ${ }^{3,5,6}$.

Prosseguindo com as caracterizações, os fluidos de corte de estado líquido são, dentre os três citados, os mais importantes e também os mais empregados devido aos fatores como menor custo de aquisição, diversidade de produtos, facilidade de uso, inúmeras características positivas para o processo. Contudo, por existir uma maior variedade, a classificação altera de acordo com a literatura ${ }^{3,6}$.

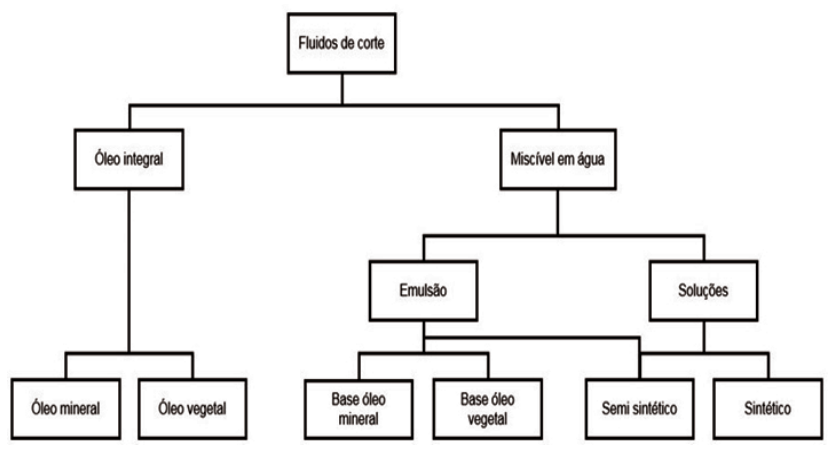

Figura 1: Classificação dos fluidos de corte. Fonte: DINIZ ${ }^{4}$.
Conforme a Figura 1, os fluidos de corte são divididos em óleos integrais e miscíveis em água (emulsionáveis e/ou soluções), mas, essa classificação é adotada em bibliografias no início do século XXI, tendo sido expandido nos novos conteúdos didáticos. Como para MACHADO (2012) que mantém os óleos integrais (puros ou com aditivos) e subdivide os óleos miscíveis em água em dois grupos distintos, sendo eles, as emulsões e soluções.

Descrevendo brevemente sobre os óleos integrais, existem os vegetais e minerais, que por possuírem maior viscosidade, são recomendados para procedimentos mais pesados, com baixa velocidade de corte, garantindo um melhor acabamento superficial da peça, no entanto, seu poder de refrigeração é relativamente baixo. Outros fatores negativos são, sua alta inflamabilidade, seu elevado custo comparado aos demais e maior risco à saúde do operador, fazendo com que assim, percam espaço no mercado ${ }^{3,5}$.

Os fluidos de corte emulsionáveis, possuem esta nomenclatura, pois seguem o conceito de emulsão entre óleo e água, apresentando duas fases e sua proporção varia entre 10 a 100 partes de água, para uma parte de óleo. Normalmente, além destas emulsões, são adicionados emulsificantes, que atuam como agentes de dispersão, que auxiliam na diminuição da tensão superficial da água, pois somente assim, geram estabilidade no fluido. Vale citar que as emulsões podem variar de acordo com a base do óleo, podendo ser, vegetal ou mineral ${ }^{3,5}$.

A partir disto, o fluido que é composto predominantemente de água, adquire melhores propriedades de refrigeração e através da ação do óleo, é possível, inibir os efeitos negativos da água em contato com os metais. Contudo, essas características são diferenciadas de acordo com a concentração, sendo as de menor quantidade de óleo propícias para situações com média/alta velocidade de corte e baixo avanço, logo, as de maior quantidade de óleo quando a lubrificação se torna relevante ${ }^{3}$.

As soluções, diferente das emulsões, são monofásicas, pois como são totalmente dissolvidas em água, através de reações químicas, geram uma mistura homogênea e sem a presença de emulsificantes. São conhecidos comumente como fluidos sintéticos, tendo como base para 
sua combinação, apenas óleo vegetal, água e aditivos. Sua principal função no processo de usinagem é garantir refrigeração e proteção anticorrosiva, no entanto, com a adição de aditivos específicos, sua diversidade de propriedades podem aumentar, elevando também seu custo de mercado ${ }^{3-5}$.

As bibliografias utilizadas para este estudo destacam que os fluidos de corte semissintéticos, que são basicamente emulsões que utilizam óleo mineral (de 5\% a 50\%), juntamente com aditivos e reagentes químicos, apresentam as mesmas funções dos fluidos sintéticos, entretanto, sua classificação como soluções ou emulsões, ficam a critério dos autores. A partir dessas informações já descritas, fica explicita a importância dos aditivos nas composições de fluidos de corte, sendo necessária a utilização dos mesmos em diversas ocasiões, pois tendem a acrescentar positivamente no processo, adicionando novas características e melhorando os demais atributos. Para um melhor compreendimento sobre os aditivos, segue abaixo sua categorização: ${ }^{3,5,6}$

\section{ADITIVOS}

Anticorrosivos: Conhecidos também como inibidores de corrosão, são substâncias químicas que impedem a corrosão tanto da peça, da ferramenta de corte e da máquina-ferramenta, visto que, normalmente a maioria dos fluidos de corte possuem água em sua composição que ocasiona essa adversidade no processo. Podem ser compostos de amina, sulfonatos, sulfurados e nitrito de sódio, sendo recomendada a utilização do nitrito de sódio em menores quantidades e com precaução, pois é suspeito de ser cancerígeno ${ }^{3-8}$.

Detergentes: Têm a finalidade de impedir ou reduzir a formação de partículas sólidas na superfície do fluido (lodo ou borras). São adquiridos através de fenolato, salicilato compostos organometálicos (apresentam ao menos um átomo de metal ligado a um átomo de carbono), juntamente com magnésio, cálcio, bário e até mesmo álcoois ${ }^{3-8}$.

Antiespumantes: Impossibilitam a formação de espumas que dificultam a visibilidade da região peça/ferramenta e interferem negativamente na refrigeração, durante a execução do processo. Interagem na tensão interfacial (água e óleo), reduzindo-a, fazendo com que as bolhas menores, aglomerem-se, criando assim bolhas maiores e instáveis. Para oferecer estas características, são utilizados polímeros de silício ou ceras especiais ${ }^{3-8}$.

Emulsificantes: Como já citado, os agentes emulsificantes ou emulgadores possuem a função de reduzir a tensão superficial da água, realizando assim a emulsão com o óleo, criando uma mistura bifásica e estável. Dentre as substâncias, há: sabões (potássio e alcanolaminas), sulfonatos de petróleo e emulsificantes não iônicos ${ }^{3,8}$.

Surfactantes: Possuem o conceito similar dos emulsificantes, contudo, realizam esta função de maneira distinta. Quando em contato com líquidos que não se misturam, como no caso da água e do óleo, suas substâncias interagem na região delimitada como área de interação dos dois fluidos, criando uma relação entre as moléculas miscíveis em água com a própria água e do mesmo modo com o óleo e as demais moléculas, garantindo homogeneidade na emulsão. Geralmente são utilizados sulfonatos, álcoois etoxilados e ésteres fosfatos ${ }^{3,8}$.

Biocidas: São substâncias que devem impedir a geração e proliferação de microrganismos (bactérias, fungos e leveduras), preservando o fluido de corte e estendendo sua vida útil. Para prevenir essa contaminação, os aditivos biocidas levam como base o enxofre, porém podem dispor de aditivos nitratos ou saia (cobre ou quaternários de amônio) $)^{3-8}$.

Aditivos de extrema pressão (EP): Estes aditivos possuem características lubrificantes, sendo recomendados para operações de usinagem consideradas mais pesadas, onde o fluido é exposto a altas temperaturas e pressões de corte. Reagem na superfície usinada, resultando na maioria das vezes, na formação de sais que em contato com elevadas temperaturas, dissolvendo-se favorável o cisalhamento. Esses atributos são adquiridos por compostos de enxofre, fósforo ou cloro, cloroparafina e ésteres (sulfuroso ou ácido fosfórico) ${ }^{3-8}$.

Diante o contexto do acréscimo de aditivos nos fluidos, pode-se levar em consideração que este é uma das formas de tentar inibir os pontos negativos em que o fluido de 
corte, seja ele mineral ou vegetal, tem dentro do processo de usinagem. Essa adição impacta diretamente em todos os parâmetros que estão envolvidos na operação, sejam de desbaste ou acabamento, por vez melhoram drasticamente a qualidade final da peça que será usinada, entregando assim um produto com características mecânicas garantidas por meio da utilização correta da mistura densa de óleo em combinação com água e aditivos diversos.

\section{INFLUENNCIA DO FLUIDO DE CORTE NA USINAGEM EM OPERAÇÕES DE DESBASTE E ACABAMENTO}

Em operações de desbaste, o ponto principal na qual o fluido de corte atuará será na lubrificação, visto que, nestes tipos de operações as temperaturas atingidas nos momentos de contato entre ferramenta e peça, não são elevadas como é em operações de acabamento. Outro ponto que pode ser considerado, é que além do fluido agir como lubrificante em baixas velocidades de corte, também ajuda na não formação de arestas postiça de corte $^{5}$.

Já nas operações de acabamento, o fluido de corte terá como finalidade principal o resfriamento, tendo potencial de aumentar a velocidade de corte em até três vezes, em razão disto, interfere de maneira positiva na qualidade superficial da peça, na rugosidade e tolerância dimensional, porém, os itens já mencionados, dependem de três fatores, sendo eles a geometria da ferramenta, as condições de corte e o comportamento dinâmico da máquina ${ }^{3}$.

O fluido de corte além de ajudar no resfriamento e lubrificação, consegue remover cavaco da zona de corte e segundo MACHADO (2012) $)^{5}$, “A capacidade do fluido de corte em remover os cavacos da zona de corte depende da sua viscosidade e vazão, além, é claro da natureza da operação de usinagem e do tipo de cavaco que está sendo formado".

Agarantia de que o material não perca suas características mecânicas é essencial, pois este, reduz gastos adicionais que proveriam de possíveis deformações na peça usinada. Portanto, o profissional habilitado para realizar o processo referido, tem que estar informado sobre os métodos e as inovações que podem ser aplicados, sendo esse último, uma prática diferenciada na qual pode resultar em pontos positivos ou negativos no processo, além das características do material trabalhado, para assim, selecionar o melhor tipo de fluido de corte em sua operação, melhorando o desempenho, garantindo qualidade e reduzindo custos.

\section{MÉTODOS DE APLICAÇÃO DOS FLUIDOS DE CORTE E INOVAÇÕES TECNOLÓGICAS}

Um método que veio como uma alternativa para redução da contaminação causada ao operador pelo fluido de corte no processo de usinagem é a técnica de mínima quantidade de fluido e sem fluido de corte (corte a seco). Como uma das maiores preocupações mundiais é em relação aos danos causados ao meio ambiente, não seria diferente uma análise voltada para a redução dos contaminantes que são liberados pelos fluidos, sendo que estes provocam não só a poluição ambiental, mas também, dificuldade e custo da reciclagem do fluido e dos cavacos que foram molhados por eles, doenças de pele e pulmão nos operadores. Um ponto crucial nesse método, é o controle da quantidade de fluido, visto que, cada processo necessita de uma quantidade diferente de lubrificação. Para garantir que o processo seja eficiente mesmo utilizando quantidades inferiores de fluido, é necessário que as condições de usinagem sejam favoráveis para o processo e que as ferramentas possuam baixo coeficiente de atrito, com alta dureza a quente e estabilidade química. O custo com o processo é um fator primordial, e mesmo que as condições implicadas para melhoria das ferramentas devido às condições de fluido sejam elevadas, o custo total de produção pode ser menor em relação aos que utilizam vazões maiores. A técnica de MQF (Mínima Quantidade de Fluido de Corte) possui boa capacidade de lubrificação e é empregada em forma de vapor devido sua maior penetrabilidade ${ }^{4,9}$.

Outra técnica anteriormente mencionada, é o corte a seco, embora tem-se a perda das vantagens que o fluido de corte proporciona ao processo, o ganho relativo à eliminação da aquisição e em manutenção desse bem, como danos ao meio ambiente e saúde do operador são fatores que compensam a utilização dessa técnica. Para aprimorar o processo de usinagem para que ele se encaixe 
sob as condições ideais de usinagem a seco, esse tem que ser realizado com aumento do avanço e diminuição da velocidade de corte. Devido à elevação do parâmetro de avanço, o contato entre ferramenta e cavaco será maior, portanto, uma maior área receberá calor gerado no processo, por conseguinte, menor temperatura na ferramenta. Esse processo acarretará em um aumento na rugosidade da peça, e para manter essa característica uniforme, é necessário aumentar o raio da ponta da ferramenta, isso resultará em um acréscimo do comprimento de contato da aresta da ferramenta com a peça, ajudando a disseminar todo o calor gerado favorecendo assim, o processo de corte a seco ${ }^{4,9}$.

A técnica de usinagem que utiliza resfriamento criogênico também é uma grande tendência tecnológica, uma vez que essa é uma boa alternativa em relação à agressão ambiental, porque o nitrogênio líquido utilizado para resfriamento no processo evapora no ar e não tem poder de contaminação e não precisa ser descartado. Esse método possui um bom rendimento com velocidades de corte mais baixas, aumentando a vida da ferramenta que é um fator preponderante no processo de usinagem. Os cavacos gerados são isentos de contaminação, podendo assim, ser reciclados e garantindo ao processo um maior aproveitamento de material sem desperdícios. O ponto negativo desse método, é a regulagem da vazão e pressão do nitrogênio, pois, implica refrigeramento excessivo da peça, aumentando as forças de corte ${ }^{4,9}$.

Uma das formas mais práticas de aplicação dos fluidos de corte é por jato à baixa pressão ou por gravidade. Esse método consiste em lançar o fluido na saída da ferramenta ou na parte superficial superior do cavaco. Como neste processo o fluido vai em oposição à superfície fraturada do cavaco, facilitando a saída para fora da interface cavacoferramenta, promovendo a remoção de cavaco da zona de corte e garantindo qualidade no processo. Pelo processo ser simples, é o mais usual.

Outro tipo de aplicabilidade é o conhecido por sistema a alta pressão. Este tem por objetivo a quebra do cavaco, onde o fluido é disparado em duas posições, sendo a primeira sobre o cavaco e a segunda na saída da ferramenta. A grande vantagem desse método é que foi desenvolvido um sistema em que agrupamento entre suporte e ferramenta de corte fossem vazados ISCAR (1991), admitindo com que o fluido passe pelo seu interior e alcançando a superfície de saída da ferramenta. Por consequência, o fluido de corte atinge a interface com alta pressão, fazendo com que o contato entre ferramenta e cavaco seja reduzido, e assim, a vida útil da ferramenta é assegurado, além da qualidade do trabalho realizado pelo processo. Nesse tipo de emprego do fluido de corte, a ferramenta sempre manterá seu interior e a superfície de saída sendo resfriados, e o cavaco, será resfriado logo após sua deformação, e na primeira direção de aplicação, o cavaco é resfriado simultaneamente à sua deformação. Como resultado desse sistema de refrigeração no processo, ocorre um aumento da resistência ao cisalhamento no material da peça e, consequentemente, as forças de usinagem sofrem uma ascensão. Com todas essas maneiras de aplicação de fluidos e as tendências tecnológicas, é perceptível a preocupação em relação às configurações dos procedimentos realizados nos processos de usinagem, uma vez que, essas interferem indiretamente no meio ambiente devido à geração de calor e emissão de gases, que são vistos como um potencial de periculosidade alto e que podem prejudicar e degradar o sistema ambiental como um todo ${ }^{6}$.

\section{CONTROLE AMBIENTAL}

Nos últimos tempos, a preocupação com o meio ambiente vem sendo pauta em principais discursos e notícias, devido a grandes empresas de vários segmentos terem poluído o ambiente em sua volta com descarte de gases e líquidos não tratados diretamente em rios ou nascentes. O governo tem órgãos responsáveis pela criação de leis e fiscalização se as empresas cumprem o tratamento antes do descarte ou até mesmo meios de descarte corretos.

A indústria metal mecânica ao final de um processo de fabricação, pode gerar diversos tipos de materiais para descarte, metal que foi retirado durante os processos, fluidos também utilizados no processo. Após todo o uso do fluido de corte na usinagem, que por sinal traz grandes benefícios ao processo, encontrasse um problema quando sua vida útil termina, como realizar o descarte correto sem agredir o meio ambiente. Muitas vezes o fluido quando foi muito 
utilizado e por um longo período de tempo, apresenta $\mathrm{pH}$ irregular, suas características químicas se alteram devido à formação de bactérias proveniente da falta de circulação do mesmo na máquina, com isso, o seu descarte se torna um tanto quanto complicado.

Segundo o Conselho Nacional do Meio Ambiente $(\text { CONAMA })^{10}$, na resolução de número 9/93, diz que "Considerando que o uso prolongado de um óleo lubrificante resulta na sua deterioração parcial, que se reflete na formação de compostos tais como ácidos orgânicos, compostos aromáticos polinucleares, "potencialmente carcinogênicos", resinas e lacas, ocorrendo também contaminações acidentais ou propositais". Esses efluentes quando liberados em rios, geram uma camada oleosa na superfície da água, dificultando a troca de oxigênio com o ambiente. Nesses fluidos também podem ser encontradas bactérias, que, quando em contato com a comunidade biológica presente no rio, podem trazer danos, desestabilização e até degradação total.

Os fluidos não apresentam apenas riscos para o meio ambiente, mas também ao operador do equipamento quando não se usa os EPIs corretamente. Como na usinagem o atrito entre a peça e a ferramenta é alto, gera-se calor, com isso, o contato do fluido com partes quentes, sejam elas a peça, ferramenta ou cavaco, gera névoa e gases que podem ser nocivos à saúde humana, também podendo alguma partícula de fluido entrar em contato com a pele e causar irritação. Fluidos integrais são mais prejudiciais à saúde, podendo chegar a riscos cancerígenos em alguns órgãos, mesmo que não sejam tão agressivos, outros tipos de fluidos também podem causar alguma irritação ou desenvolvimento de alguma doença, podendo piorar quando misturados com aditivos inadequados.

Algumas fábricas contam com centrais de reciclagem, que recuperam o fluido de corte, retirando impurezas e partículas de metais. Porém mesmo com tantas etapas e processos na reciclagem pode-se tornar uma atividade com alto custo financeiro, devido aos equipamentos, local e material e inviável devido ao fluido não apresentar características idênticas quando se está novo, podendo assim ter uma menor vida útil e além de trazer danos ao equipamento. Quando o óleo é filtrado, retira-se os cavacos de usinagem e são separados, esses cavacos devem ser tratados com cuidado, pois ainda estão úmidos com fluido, se o transporte não for adequado, esse fluido irá escorrer por vãos das carrocerias dos caminhões de transporte e contaminar o solo por onde passa ${ }^{11}$.

Um problema encontrado também é o descarte do cavaco após a usinagem, mesmo após o transporte correto, quando descartado no solo, a contaminação é alta devido à presença de fluido e ao metal que demora vários anos para se decompor. Logo é preciso de um meio para a reciclagem desse material também, para que não seja despejado em local e de maneira incorreta ${ }^{12}$.

Existem duas classificações quanto ao tipo de tratamentos de fluidos de corte, sendo químicos e físicos. Os químicos agregam a quebra ácida, que consiste na adição e agitação da emulsão juntamente com ácido, após isso, deixa-se decantar, logo em seguida é retirado o óleo e sobrando uma "lama" no tanque, não sendo necessária a remoção para o próximo tratamento. Outro modo químico é por meio de polímeros, adicionando-se polieletrólitos na emulsão, gera-se floculação da emulsão. Os métodos físicos agregam tanques de decantação, realizando a quebra química e separação das fases, outro meio é a separação por membranas que se divide em três processo: microfiltração, ultrafiltração e osmose reversa. Esses processos consistem em passar a emulsão através das membranas, porém o óleo não é totalmente separando da água, necessitando de outro tipo de tratamento. Posteriormente, também para a retirada da água da emulsão, pode-se utilizar a técnica de evaporação, na qual inicialmente são retirados todos os outros resíduos de óleos distintos da máquina e os resíduos, logo em seguida, a emulsão é levada para evaporadores que permitem apenas a evaporação da água por meio de temperaturas controladas ${ }^{12}$.

Com base nas pesquisas bibliográficas e nos conhecimentos mencionados, o objetivo deste trabalho científico é analisar os fluidos de corte utilizados no equipamento "Torno CNC Romi Centur 30D”, do Centro Universitário de Anápolis - UniEVANGÉLICA, realizando assim os testes químicos e físicos que avaliam a degradação durante um período de utilização e armazenagem no 
equipamento, gerando assim uma comparação entre os fluidos utilizados. Durante a realização da pesquisa, foram empregados ao equipamento dois tipos diferentes de fluidos de corte, sendo eles o fluido vegetal e fluido mineral, ambos solúveis em água.

\section{Metodologia}

Inicialmente foi coletada uma amostra do fluido (coleta 1) que estava no equipamento, para análise comparativa, posteriormente, realizou-se a troca para um novo fluido de corte vegetal (coletas 2 a 7), sendo ele, Óleo solúvel biodegradável, da marca Vonder, lote $\mathrm{n}^{\mathrm{0}} 214$, permanecendo em uso durante 70 dias. Neste período, foram coletadas 6 amostras em intervalos de 13 a 15 dias, entre uma coleta e outra. Ao longo de 27 dias, ocorreu a interrupção da pesquisa, devido à degradação excessiva do fluido no equipamento, impossibilitando o uso deste, fazendo com que as coletas retornassem quando um novo fluido de corte fosse adquirido e realizado a troca no reservatório do torno $\mathrm{CNC}$.

Após a troca de fluidos, foi empregado o fluido de corte mineral Sivalane Solúvel Extra (coletas 8 a 12), da marca Siva Siroll, lote $n^{\circ} 08 / 04$, permanecendo em uso em um período de 70 dias, para que os períodos de trabalho e intervalo de dias entre as coletas fossem idênticos ao fluido anterior, resultando em apenas 5 amostras coletadas, devido à falha no procedimento de coleta e armazenagem a amostra do dia 03 de agosto de 2019 foi indisponibilizada e descartada. Ambos os fluidos estavam contendo a mesma concentração dentro do reservatório, sendo ela de 1 parte de óleo, para 20 partes de água.

Todas as amostras foram armazenadas em frascos de vidro âmbar $(200 \mathrm{ml})$, previamente higienizados com água corrente e detergente neutro e esterilizados com álcool $70 \%$. Foram identificados com o tipo de fluido e data da coleta, logo em seguida, estocados até a última data de coleta, para realização dos testes físicos e químicos. Dentre os testes químicos realizados, há: $\mathrm{pH}$, condutividade elétrica e densidade. As amostras foram colocadas em Becker de 100 $m l$ e enumeradas de acordo com a Tabela 1 .
Tabela 1: Dados das coletas. Fonte: Autores.

\begin{tabular}{cccc}
\hline $\begin{array}{c}\text { NÚMERO DA } \\
\text { AMOSTRA }\end{array}$ & $\begin{array}{c}\text { TIPO DE FLUIDO } \\
\text { DE CORTE }\end{array}$ & DATA DA COLETA & $\begin{array}{c}\text { TEMPODE PERMANÊNCIA } \\
\text { NO TORNO CNC (dias) }\end{array}$ \\
\hline 01 & Vegetal & $27 / 03$ & Indeterminado \\
02 & Vegetal & $27 / 03$ & 0 \\
03 & Vegetal & $10 / 04$ & 14 \\
04 & Vegetal & $24 / 04$ & 14 \\
05 & Vegetal & $09 / 05$ & 15 \\
06 & Vegetal & $22 / 05$ & 13 \\
07 & Vegetal & $05 / 06$ & 14 \\
08 & Mineral & $04 / 07$ & 0 \\
09 & Mineral & $19 / 07$ & 15 \\
10 & Mineral & $16 / 08$ & 13 \\
11 & Mineral & $29 / 08$ & 13 \\
12 & Mineral & $12 / 09$ & 14 \\
\hline
\end{tabular}

Para a realização da aferição do $\mathrm{pH}$, foi utilizado um medidor de $\mathrm{pH}$ (pHmetro), modelo Q-400A da marca QUIMIS. Em cada amostra, o eletrodo foi posicionado dentro do Becker de $200 \mathrm{~mL}$, até a estabilização da leitura, tendo o resultado mostrado no visor. A medição da condutividade elétrica foi realizada por meio de um condutivímetro portátil da marca QUIMIS, modelo Q-795P. O equipamento é interligado a um eletrodo, no qual foi submergido dentro da amostra, logo em seguida aguardaram-se cerca de 5 minutos até a estabilização dos dados mostrados no visor.

Para a medição da densidade de cada amostra, foram utilizados Picnômetros de $25 \mathrm{~mL}$, cada um foi pesado individualmente vazio, juntamente, com sua tampa em uma balança de precisão devidamente calibrada. Em seguida, foi adicionado a amostra do fluido de corte dentro da vidraria e foi levado à balança novamente, com isso o resultado foi obtido mediante a diferença da massa entre as duas etapas de pesagem pelo volume do Picnômetro.

$O$ teste de viscosidade foi realizado com um viscosímetro, da marca QUIMIS, modelo Q860M21, que possuía 4 Spindles, no qual cada um desses era destinado a um nível de viscosidade, sendo o Spindle 1 para menores viscosidades e o Spindle 4 para maiores viscosidades. $\mathrm{O}$ equipamento ainda contava com duas velocidades de 
rotação (30 e 60 rpm). O Spindle utilizado foi o de número 1 , em uma rotação de $60 \mathrm{rpm}$, pois apenas com estes parâmetros era possível obter um resultado no visor. As amostras foram colocadas em Beckers de $200 \mathrm{~mL}$ e o rotor do equipamento foi submergido até o nível necessário. Após isso, foi acionado e aguardado um minuto até a estabilização do resultado, com isso a amostra era retirada e o visor apresentava o valor final, sendo este apresentado em Pascal $\times$ Segundo (Pas). Contudo para melhor comparação com as bibliografias, é necessária a conversão para outras duas unidades, sendo a primeira Centipoise $(\mathrm{cP})$ e a segunda Centistokes (cSt).

A conversão de (Pas) para (cP) é apenas uma multiplicação por um mil (x1000), pois (cP) é o mesmo que milipascal $\times$ segundo (mPa.s) sendo ambas unidades de viscosidade dinâmica. Já a conversão de (Pas) para (cSt), exige a alteração de viscosidade dinâmica para viscosidade cinemática (viscosidade absoluta / densidade), necessitando assim da multiplicação do resultado em (cP) vezes o inverso da densidade, conforme Equação $1^{13}$.

$$
c S t=c P * \frac{1}{\text { Densidade }}
$$

Para realização entre as amostras de todos os experimentos, os equipamentos foram higienizados com água destilada e álcool $70 \%$, a fim de evitar qualquer contaminação entre as amostras. A partir dos dados coletados, foram elaborados gráficos para melhor visualização dos resultados e comparação com o referencial teórico que é relacionado com este tema.

\section{Resultados e Discussão}

Primeiramente, foi realizada a análise do $\mathrm{pH}$ dos fluidos de corte, sendo necessária a comparação com as fichas técnicas de ambos os fluidos. O fluido vegetal não apresenta dados concretos com relação à sua composição, sendo de 80 a $90 \%$ segredo industrial, 10 a $20 \%$ de óleo vegetal e de 1 a $5 \%$ Dietanolamina, dificultando assim a apuração de dados.
O fluido mineral por mais simples que seja sua composição (85\% Óleo Mineral, 15\% Emulgadores) não apresenta o valor do seu $\mathrm{pH}$ em sua ficha técnica, inviabilizando sua comparação com os resultados ${ }^{14,15}$.

$\mathrm{Na}$ Figura 2 é apresentado o valor do $\mathrm{pH}$ de cada amostra, sendo levado em consideração os dias das coletas e as horas trabalhadas entre estes períodos. Pode-se notar que quando o equipamento possui algum valor de horas trabalhadas, por menor que sejam, o pH tende a subir, apresentando características de base. O contrário também acontece quando o fluido fica em estado estacionário, tendo uma queda brusca do seu $\mathrm{pH}$ atingindo características de ácido, sendo altamente prejudicial para o maquinário.

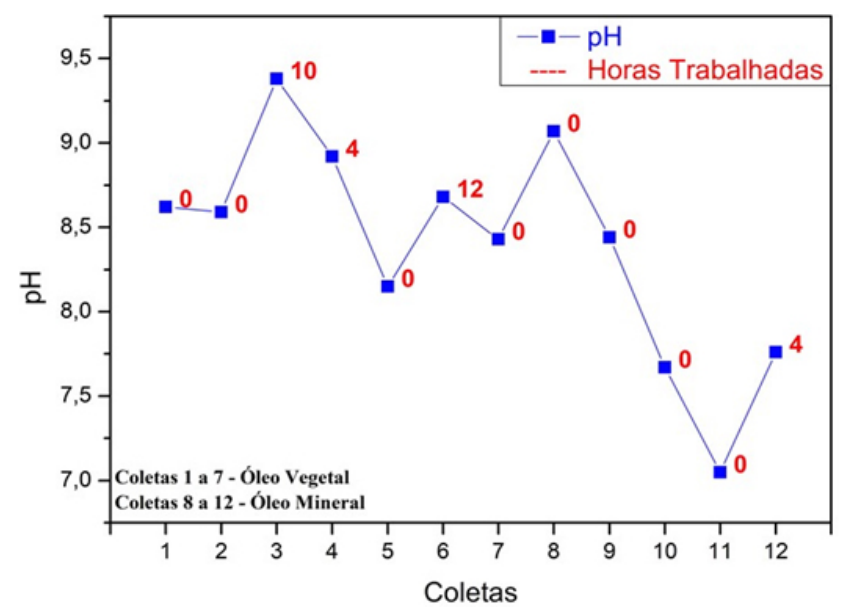

Figura 2: pH x Coleta. Fonte: Autores.

As amostras de fluido de corte vegetal apresentaram certa discrepância com os valores informados na ficha técnica do produto ( $\mathrm{pH} 9$ a 10), em que valores próximos a estes só foram alcançados com a utilização do fluido a partir de 10 horas de trabalho. Levando em consideração o fluido de corte mineral, este não apresenta o valor do seu $\mathrm{pH}$ em sua ficha técnica. No entanto é perceptível uma queda brusca do seu $\mathrm{pH}$, chegando ao valor de 7 , no qual o fluido adquire propriedades de uma solução neutra ${ }^{14,15}$.

Segundo MARCELINO (2012) ${ }^{16}$, o nível do $\mathrm{pH}$ para ser aceito nas indústrias deve ter valor a partir de 8,7 , valores que estejam entre a faixa de $8,7-7,8$ é recomendada a 
utilização de aditivos para o controle. Entretanto, caso o pH do fluido seja abaixo de 7,8 a ação mais recomendada é que seja realizado a troca do fluido. Abordando também outro fator importante, sendo o de contaminação de microrganismos, a partir do estudo de CARVALHO (2017) $)^{17}$ é compreendido que, a diminuição do $\mathrm{pH}$ é um indicativo da existência de bactérias ou fungos dentro do fluido de corte, podendo ser denotado também por fatores como: odor, diminuição das vidas úteis da ferramenta e do fluido, corrosão, dentre outros ${ }^{18}$.

A condutividade elétrica é relacionada com a capacidade de um material conduzir ou inibir eletricidade, neste caso aumenta conforme a quantidade de metais que entram em contato com o fluido de corte, pois quando pequenas partes do cavaco ficam imersas sobre o fluido de corte em estado estacionário, é iniciado um processo de corrosão do metal, mais especificamente uma corrosão eletroquímica, neste caso sofrendo efeito da solução aquosa do fluido onde o metal, formado por átomos de ferro $(\mathrm{Fe})$, libera os elétrons $\left(2 \mathrm{e}^{-}\right)$para o meio que está envolvido:

$$
F e_{(s)} \rightarrow F e^{2+}+2 e^{-}
$$

Estes elétrons que entram em contato com o fluido, aumentando sua condutividade, buscam estabilizar-se juntamente com os átomos de água $\left(\mathrm{H}_{2} \mathrm{O}\right)$ e oxigênio $\left(\mathrm{O}_{2}\right)$, através de um balanceamento químico e conforme o trabalho de FRAUCHES-SANTOS (2014) ${ }^{19}$, quando o meio é considerado básico ou neutro com presença de oxigênio, como o caso deste estudo, formam assim a seguinte equação química:

$$
\mathrm{H}_{2} \mathrm{O}+\frac{1}{2} \mathrm{O}_{2}+2 e^{-} \rightarrow 2 \mathrm{OH}^{-}
$$

Portanto são obtidas duas moléculas de hidroxila, que ao entrar em contato com as moléculas de $\left(\mathrm{Fe}^{+}\right)$, formam o hidróxido de ferro $\left(\mathrm{Fe}(\mathrm{OH})_{2}\right)$, que presente em um meio aquoso alcalino, realiza a quebra das moléculas (hidrólise), liberando assim átomos de óxido de ferro II ( $\mathrm{FeO})$, não se descarta a possibilidade da liberação de óxido de ferro III $\left(\mathrm{Fe}_{2} \mathrm{O}_{3}\right)$, ambos contribuem para a mudança de coloração de fluido, tornando-o amarronzado ${ }^{18}$.

$$
2 \mathrm{Fe}(\mathrm{OH})_{2}+\frac{1}{2} \mathrm{O}_{2}+\mathrm{H}_{2} \mathrm{O} \rightarrow 2 \mathrm{Fe}(\mathrm{OH})_{3} \mathrm{Ou} \mathrm{FeO.OH} \mathrm{(Eq.} \mathrm{04)}
$$

AFigura 3 demonstra o comportamento da condutividade elétrica de acordo com o período de tempo avaliado, tendo um maior acréscimo principalmente no fluido vegetal, devido ao maior número de horas trabalhadas. É possível notar também a diferença de condutividade quando os fluidos são recém colocados no reservatório. Portanto, o fluido de corte vegetal tem uma maior tendência a formar os óxidos de ferro citados, aumentando assim os aspectos da coloração de tom marrom dentro do tanque.

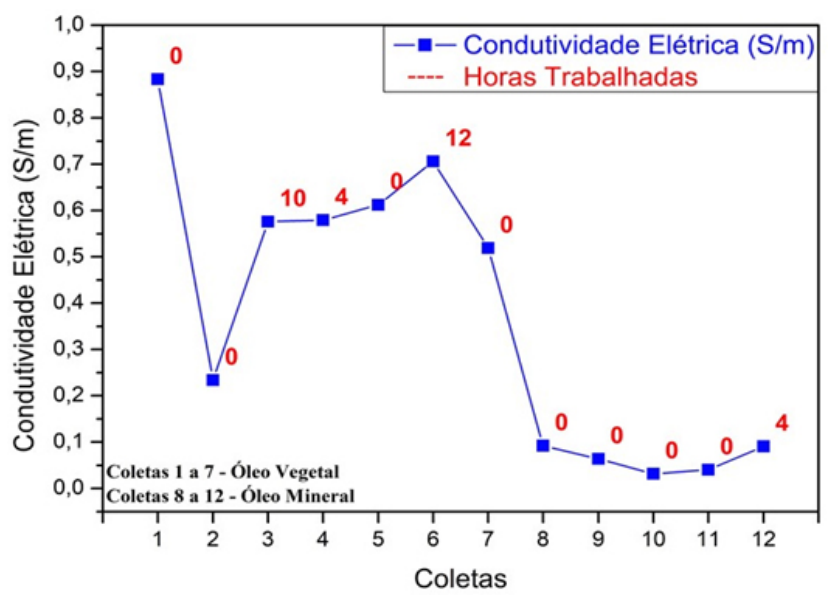

Figura 3: Condutividade Elétrica x Coletas. Fonte: Autores.

Como as fichas técnicas não informam as respectivas condutividades dos fluidos de corte, o teste de condutividade elétrica é direcionado para demonstrar o crescimento de substâncias corrosivas (óxido de ferro) dentro da solução, que além de aumentar o $\mathrm{pH}$, podem acarretar possíveis problemas ao equipamento, caso não 
possua tratamentos químicos durante sua fabricação ou sofra ranhuras na camada de proteção do material. Comparando os dados do fluido mineral com os resultados encontrados por MARCELINO $(2013)^{20}$, pode-se verificar que os valores encontrados durante o ensaio condizem com os apresentados pelo autor, em que após 6 meses de seus estudos, verificou-se um aumento de $0,07506 \mathrm{~S} / \mathrm{m}$ para os dados do autor e de $0,06040 \mathrm{~S} / \mathrm{m}$ para o fluido mineral analisado neste estudo de caso ${ }^{14,15}$.

A densidade de um fluido, é a relação de massa $(g)$ por seu volume $\left(\mathrm{m}^{3}\right)$, estes valores podem se alterar de acordo com a proporção de óleo e água utilizados nos devidos fluidos. O teste de densidade, além de fornecer dados para comparação com as devidas fichas técnicas, teve como intuito principal informar estes valores para a elaboração dos cálculos de conversão para o teste de viscosidade, além do mais, é visível o comportamento dessa no decorrer da vida útil dos fluidos, conforme Figura 4.

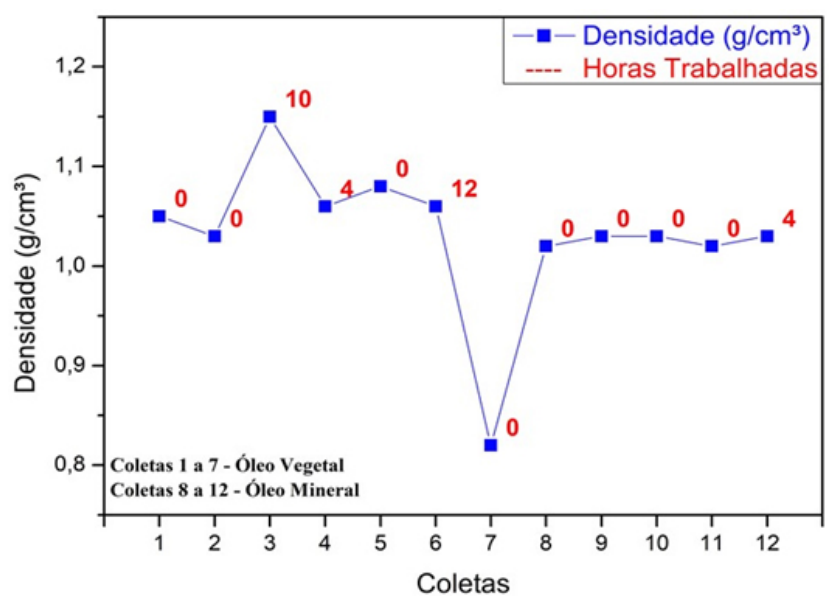

Figura 4: Densidade x Coletas. Fonte: Autores.

Ao analisar o comportamento da densidade dos fluidos é perceptível uma discrepância com o passar do tempo, mais evidentemente no fluido de corte vegetal. Isto se deve ao fato de que teve uma maior carga horária de trabalho, entrou em contato por mais tempo com o cavaco gerado pelo processo, o que deve ter ocasionado uma adição de pequenas partículas de ferro, com o passar das quinzenas, o metal acumulado no fluido entrou em processo de oxidação e formou uma borra de ferrugem, por possuir uma menor densidade que o fluido, acabou acumulando-se na superfície do reservatório. Durante as coletas, como possuía forte odor e dificultava armazenagem, programou-se para evitar a coleta do fluido com grande partes de resíduo superficial.

Essa proposta para coleta pode ter ocasionado estes valores divergentes para avaliação. Entretanto, ao avaliar a ficha técnica do fluido de corte vegetal, fica compreendido que os dados coletados estão de certa forma, coerentes com a ficha, por que a mesma apresenta uma densidade de 1,02 a $1,05 \mathrm{~g} / \mathrm{cm}^{3}$ e como a maior parte da solução é água, apresentaria um valor próximo de $0,997 \mathrm{~g} / \mathrm{cm}^{3}$ a $25^{\circ} \mathrm{C}$. A última coleta do fluido vegetal teve um alto índice de decaimento da densidade, provavelmente, ocasionado pela perda precoce da vida útil. O fluido de corte mineral, por sua vez, não teve horas trabalhadas nas primeiras coletas, por isso, manteve sua densidade constante em todo o período de avaliação, tendo um pequeno acréscimo, devido à soma de 4 horas trabalhadas na última coleta ${ }^{14,15}$.

Em sua ficha técnica, apresenta densidade de $0,877 \mathrm{~g} /$ $\mathrm{cm}^{3}$ e com a adição de água, a densidade do mesmo tendeu a elevar, o que é perceptível a olho nu quando misturado o fluido puro com água. $\mathrm{O}$ estudo da densidade dos fluidos de corte não possui um direcionamento tão específico e, na maioria das vezes, são realizados com intuito de comparação com a ficha ou norma técnica desses. Comparando os resultados com diversos autores, as densidades encontradas são bem equivalentes e coerentes com as especificações de sua utilização, variando de acordo com a concentração e temperatura durante análise ${ }^{14,15}$.

Do mesmo modo que os demais ensaios realizados, foi necessário primeiramente conferir a ficha técnica de ambos os fluidos para prosseguir com a comparação da viscosidade, em que respectivamente os valores são: 40 a 90 cSt para o fluido vegetal e 10,2 cSt para o fluido mineral. Torna-se necessário realizar a conversão de unidades para análise dos dados e de acordo com a Figura 5 são exibido os valores coletados da viscosidade em duas unidades 
dinâmica $(\mathrm{cP})$ e cinemática $(\mathrm{cSt})$. Algumas amostras não apresentaram resultado no dispositivo, devido à baixa faixa de valores que possui, tornando assim um fator limitante ${ }^{13}$.

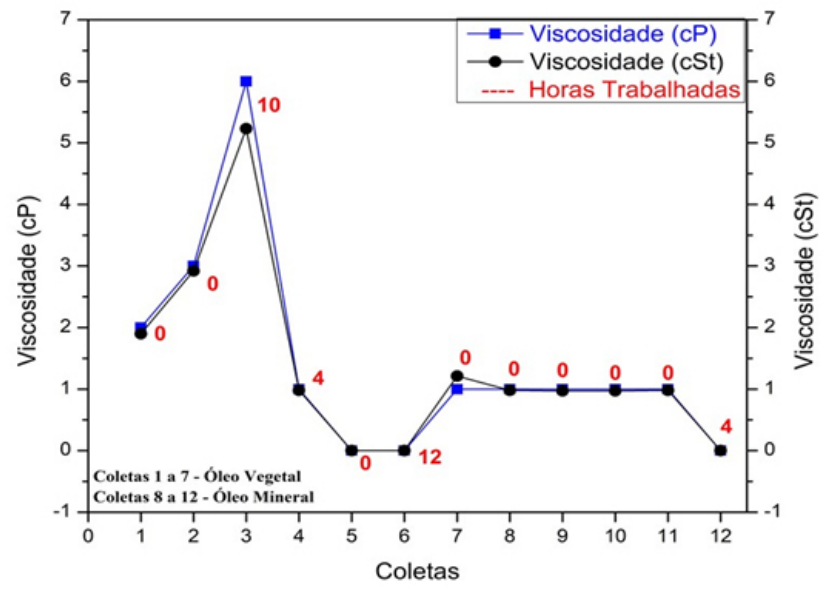

Figura 5: Viscosidade x Coletas. Fonte: Autores.

Analisando os valores obtidos na Figura 5, é possível observar que os resultados das amostras de fluido de corte vegetal decaem drasticamente, isso é devido à possibilidade de o fluido vegetal ter ocorrido uma proliferação de microrganismos, juntamente com partículas metálicas da usinagem realizada, o que fez esse ter uma característica refrigerante maior que a de lubrificante, acarretando também em instabilidade na viscosidade, devido a sua baixa vida util. O fluido mineral teve uma constância em seus valores pelo fato de ter poucas horas de trabalho, obtendo-se uma característica de refrigerante dominante $\mathrm{e}^{14,15,17}$.

A partir das premissas acima sobre os resultados gerados tornou-se possível a avaliação com o estudo de CARVALHO $(2017)^{17}$, no qual a autora analisa o desempenho de dois fluidos de corte, um de origem vegetal e outro mineral. Os valores alcançados através dos testes de viscosidade apresentam compatibilidade com os encontrados neste trabalho, no qual os valores encontrados pela autora foram, para o fluido de corte vegetal é encontrado entre uma faixa de 1,13 a 6,46 cP $(1,14$ a $6,53 \mathrm{cSt})$ e para os fluidos de corte mineral de 0,81 a $1,03 \mathrm{cP}(0,81$ a $1,03 \mathrm{cSt})$. A queda de valores para a viscosidade que é observada, é explicada por meio do ataque de bactérias e fungos presentes nas emulsões, que degradam os emulgadores e a matéria orgânica presente nos fluidos, auxiliando para a instabilidade da viscosidade. Considerando que os fluidos analisados possuem diferentes porcentagens de concentração e, portanto, estes resultados se devem, de acordo com a autora, ao fato de os fluidos estão miscíveis em meio aquoso, sua viscosidade será próxima da água ${ }^{17,20}$.

Um adendo importante sobre a vida útil do fluido, não é especificado nas fichas técnicas nem em bibliografias com esta temática a validade que um fluido de corte tem no processo de usinagem. Entretanto, na placa de identificação do torno $\mathrm{CNC}$ deste estudo, é citado que a cada 6 meses deve ser feita a troca do fluido.

\section{Conclusões}

Ao finalizar as comparações e apurações de resultados, os seguintes pontos devem ser destacados, primeiramente, ambos os fluidos de corte analisados neste trabalho, possuíam um desempenho baixo durante o período de avaliação. O fluido de corte vegetal, por ser maior parte da sua composição segredo industrial, deixou alguns aspectos em dúvidas, como a presença de aditivos, especificamente detergentes e biocidas que poderiam prolongar a vida útil do mesmo. O fluido de corte mineral apresentou melhor performance devido às poucas horas trabalhadas, porém seu pH decaiu muito por esse mesmo fator, o que é um risco ao torno. Este fator de horas trabalhadas contribuiu negativamente neste caso, pois já é de conhecimento geral, que equipamentos mecânicos devem manter uma constância de funcionamento, o que não foi executado de fato, pois é calculada uma carga de 30 horas trabalhadas em um período de aproximadamente 170 dias, o que provoca a formação de problemas mecânicos dentro deste torno $\mathrm{CNC}$, desde problemas com a lubrificação dos eixos, possibilidade de travamento de partes e como visualizado, uma perda antecipada dos fluidos de corte.

Outra circunstância verificada foram as concentrações utilizadas neste torno e, segundo a própria placa de identificação do equipamento, é necessário cerca de $60 \%$ de 
fluido de corte para operações. Todavia essa recomendação é para funcionamento industrial, que exige alta porcentagem que acarreta em um acréscimo no valor, como o maquinário é utilizado para fins didáticos, não é necessário a mesma porcentagem. Porém devem-se procurar alternativas para evitar possíveis problemas, como o estudo para viabilizar a quantidade de fluido necessários em casos específicos como este.

As considerações finais devem ser: buscar novos fluidos de corte, de preferência de origem vegetal, por ser menos agressivo ao meio ambiente e ao operador, mas que possuam os aditivos já mencionados; verificar o reservatório de fluido periodicamente para a constatação na mudança de odor, coloração e surgimento de partículas superficiais, juntamente com a devida limpeza; incentivar a utilização do torno $\mathrm{CNC}$, principalmente, com a participação dos discentes do curso ou por meio de prestação de serviços em geral. Por fim o descarte correto do fluido após uso, sendo uma proposta caso possível, por meio de incineração como já ocorre com os resíduos hospitalares gerados pela instituição ou buscando a forma mais correta perante a legislação ambiental, direcionando o fluido para uma estação de tratamento adequada a este tipo de efluente.

\section{Referências}

1. Almeida PS de. Processos de Usinagem: Utilização e Aplicações Das Principais Máquinas Operatrizes. 1o. (Editora Érica, ed.). São Paulo - SP; 2015. https://integrada.minhabiblioteca.com.br/\#/ books/9788536520070/cfi/2!/4/4@0.00:7.59.

2. Quimatic T. A Influência dos Fluidos de Corte na Usinabilidade dos Metais. https://www.quimatic.com.br/blog/2016/02/a-influenciados-fluidos-de-corte-na-usinabilidade-dos-metais/. Published 2016. Accessed August 29, 2019.

3. Ferraresi D. Fundamentos Da Usinagem Dos Metais. 17o ed. São Paulo - SP: Edgard Blücher; 2017.

4. Diniz, Anselmo Eduardo; Marcondes, Francisco Carlos; Coppini NL. Tecnologia Da Usinagem Do Materiais. 9o ed. São Paulo - SP: Artliber Editora; 2014.

5. Machado ÁR, Abrão AM, Coelho RT, Silva MB da, Ruffino RTPP-SP. Teoria da Usinagem Dos Materiais. 2012:397.
6. Santos SC, Sales WF. Aspectos tribológicos da usinagem dos materiais. São Paulo Artliber. 2007;246.

7. Finzi MB de A. Fluidos de corte e suas indispensáveis e necessárias características protetivas ao sistema no qual circulam. 2017.

8. Lima HV. Análise do Comportamento do Fluido de Corte Recuperado / Reformulado no Processo de Retificação Hugo Vilaça Lima Análise do Comportamento do Fluido de Corte Recuperado / Reformulado no Processo de Retificação. 2013:117.

9. Lisboa FC de, Moraes JJB de, Hirashita M de A. Fluidos De Corte : Uma Abordagem Geral E Novas. In: Encontro Nacional de Engenharia de Produção. Salvador - BA; 2013.

10. CONAMA. Conselho Nacional do Meio Ambiente. Resolução No 9. 31/08/93.

11. Vieira C, Pasqualini A, Alexandrini F, Alexandrini CFD, Hasse CR. Reaproveitamento de Óleo de Corte em Centros de Usinagem no Setor de Suportes na Metalúrgica Riosulense S.a. 2012. https://www. aedb.br/seget/arquivos/artigos12/28416236.pdf.

12. Dandolini DL. Gerenciamento Ambiental de Fluidos De Corte Em Indústrias Metal-Mecânicas. 2001.

13. Khonsari MM, Booser ER. Applied Tribology: Bearing Design and Lubrication. John Wiley \& Sons; 2017.

14. Vonder. FISPQ - Ficha de Informações de Segurança de Produtos Químicos.; 2019:7.

15. SivaSiroll. Ficha de Informações de Segurança de Produtos Químicos (FISPQ).; 2018:9.

16. Marcelino A, Mg LIOC, Mg LRC, Mg CRC, Mg HVC. Propriedades dos fluidos de corte sem contaminação e com contaminação. In: ; 2012:1.

17. Carvalho D oliveira almeida. Comparação do desempenho de fluidos de corte de base vegetal e mineral no torneamento do aço ABNT 1050. 2017:170.

18. Fogo FC. Avaliação e critérios de eficiência nos processos de tratamento de fluido de corte por Eletroflotação. 2008:117.

19. Frauches-Santos C, Albuquerque MA, Oliveira MCC, Echevarria A. The corrosion and the anticorrosion agents. Rev Virtual Quim. 2014;6(2):293-309. doi:10.5935/1984-6835.20140021

20. Marcelino Lido, Silva LR da, Calado CR, et al. Fluido De Corte Mineral Emulsionável: Monitoramento, Análise Da Degradabilidade, Reformulação E Estratégias De Aumento De Tempo De Vida No Processo De Retificação. In: 7o Congresso Brasileiro de Engenharia De Fabricação. Vol 1. Itatiaia - RJ; 2013:130. doi:10.1017/ CBO9781107415324.004 


\section{Artigo Geral 3}

Filipe Y. G. Luz*, Bruno S. Miranda, João V. M. Torres, Sérgio $M$. Brandão \& Adriano P. Ramiro

Centro Universitário de Anápolis - UniEVANGÉLICA. Avenida Universitária, km 3,5, Centro Universitário, Anápolis, Goiás, Brasil.

*E-mail: filipe-yan@hotmail.com 